\title{
Investigating early years teachers' understanding and response to children's preconceptions
}

Article

Kambouri, M. (2016) Investigating early years teachers' understanding and response to children's preconceptions. European Early Childhood Education Research Journal, 24 (6). pp. 907-927. ISSN 1752-1807 doi:

https://doi.org/10.1080/1350293X.2014.970857 Available at https://centaur.reading.ac.uk/38108/

It is advisable to refer to the publisher's version if you intend to cite from the work. See Guidance on citing.

Published version at: http://www.tandfonline.com/doi/abs/10.1080/1350293X.2014.970857\#.VMYqU_6sV8E

To link to this article DOI: http://dx.doi.org/10.1080/1350293X.2014.970857

Publisher: Taylor and Francis

All outputs in CentAUR are protected by Intellectual Property Rights law, including copyright law. Copyright and IPR is retained by the creators or other copyright holders. Terms and conditions for use of this material are defined in the End User Agreement.

www.reading.ac.uk/centaur 
Central Archive at the University of Reading

Reading's research outputs online 


\title{
Investigating Early Years Teachers' Understanding and Response to Children's Preconceptions
}

\author{
Maria Kambouri \\ University of Reading, School of Education
}

To refer to this paper: Kambouri, M. (2017). Investigating Early Years Teachers' Understanding and Response to Children's Preconceptions. EECERJ, Volume 25, Issue 3.

Or for the online version: Kambouri, M. (2015). Investigating Early Years Teachers' Understanding and Response to Children's Preconceptions. EECERJ, Volume 25, Issue 3, http://www.tandfonline.com/doi/abs/10.1080/1350293X.2014.970857\#.VMYqU_6sV8E

\section{Introduction}

This paper focuses on Cypriot early years teaching of science and explores the teachers' response to children's preconceptions. The study acknowledges that different countries have different policies in regards to the teaching of early years science. However, it is highly possible that results and implications deriving from this study might be helpful and applicable for other countries and other subjects as well. The study's theoretical background is rooted in social constructivism, which was first developed by Vygotsky (Atherton, 2009). Social constructivism can be applicable to different subjects, contexts and learning environments, since it involves children constructing their knowledge based on what they already know; it also recognises the importance and the effect that social context can have on learning (Hoover 1996; Jaworski 1993).

The focus here is children's preconceptions at a very young age, when children first come into contact with formal educational settings. Previous research has mainly focused on older children's concepts (Valanides et al. 2000; Russell and Watt 1992; Pine et al. 2001). There is also a lack of research focusing on early years teacher's views of children's preconceptions. Consequently, there was a need for research focusing on younger children and their teachers as participants since it is important to understand early years professionals' thinking and understanding of young children's preconceptions. Teachers' understanding will be directly related to the way that they will choose to respond to preconceptions while teaching science.

Piaget was the first to put forward the notion that children construct their own knowledge which is different from that of an adult (Black \& Lucas, 1993). Children arrive into different educational environments with their own initial ideas which determine how they perceive the world (Henriques 2002). These initial ideas are developed through everyday activities which enable learning even before entering formal education (Bradley 1996; Allen 2014). As a result, different children will have different initial ideas based on their previous experiences, from which some will be preconceptions (erroneous concepts) and some will be correct concepts. In this sense, 
if children receive the appropriate guidance, they can have their own preconceptions restructured into new ones which will be correct, or at least less erroneous, when considering what is currently accepted by the scientific community (Nussbaum 1989). However, if children do not receive proper guidance there is great danger that their initial preconceptions will be restructured and developed into alternative ideas, also known as misconceptions (Valanides 2000; Johnston 2005; Kambouri et al. 2011).

Differences in individual thinking are important to recognise when children attend kindergarten and meet science as organised knowledge instead of unstructured everyday activities. Investigating children's preconceptions at an early stage is necessary not only when aiming to provide guidance for teachers' working with young children in the early years but also when aiming to improve early years education in general and children's knowledge construction in particular. Ignoring children's preconceptions at an early stage can lead to the creation of stronger alternative ideas which are often inconsistently applied and remarkably resistant to change (Black and Lucas 1993). The issue under investigation here should concern all educational systems interested in improving their early years education and it can also offer knowledge to curriculum development, policy, pedagogy and initial teacher training education. The main research questions under investigation were: 'What is early years teachers understanding of children's preconceptions? 'Do early years teachers identify children's preconceptions prior or during a science lesson, and how?' and 'Do early years teachers acknowledge children's preconceptions when developing or teaching a science lesson and how?'. Answering these questions would help develop a comprehensive understanding of teachers' response to children's preconceptions when teaching science, which is the main aim of this study.

\section{Theoretical Background}

As this study focused on Cypriot teachers' responses to young children's preconceptions it was considered appropriate to make a reference to Cyprus' educational system and National Curriculum. The Ministry of Education in Cyprus (MoEC) was established in 1965. Under this ministry, the education system for early years evolved its present structure. Early years institutions include public, private, and community-based nursery schools, day care centres, and kindergartens. Today, and since 2004, early years education is compulsory for all the children that have reached the age of four years and eight months by the 1st of September of the year their tuition is due to begin (MoEC 1996).

Cyprus has had a national curriculum for early years and primary education since its independence from Britain in 1960 with reviews been undertaken since then (Zembylas 2002). The most recent version was completed in 2011 and trialled in 2012 (Loizou and Papademetri-Kachrimani 2011). The current curriculum is the first one that was developed as an autonomous curriculum for early years and not as part of the primary education curriculum. It is based on ideas that strongly relate to the social constructivism theory and children are seen to learn together through exploring, playing, debating and participating actively in the process of constructing experiences (Jaworski 1993). Learning refers to the overall development of children and the learning process is thought to start from what children already know and aim to develop each child's understanding based on individual's capabilities. All children are considered capable and with a potential to learn and the relations between adults and children are considered to be a landmark for children's development and in this 
context parents are considered partners of the school (Loizou and PapademetriKachrimani 2011).

In this new curriculum, science and mathematics are presented together and they are sharing the same objectives. They are seen as a part of children's overall development and as a means to satisfy children's need for experimentation, play and pro-active participation. The curriculum provides a number of learning goals which are determined through six learning areas. These learning areas are: 1) Gaining experience, 2) Developing skills of scientific methods, 3) Developing skills of scientific processes, 4) Developing attitudes, 5) Developing conceptual understanding and 6) Development of epistemological preparedness (Loizou and PapademetriKachrimani 2011, 78). The fifth one directly relates to the purpose of this paper. The same document claims that during early years education, children should develop the utmost scientific process skills that are the basis of science literacy according to their individual abilities; children should be involved in scientific processes such as problem solving and investigation. Through skills' cultivation activities, children should come in contact with a variety of concepts and gain rich and varied experiences which will support the development of conceptual understanding (Loizou and Papademetri-Kachrimani 2011).

In addition, in-service early years teachers today may have graduated from the University of Cyprus or from the Pedagogical Academy of the Ministry of Education. They may also have studied at one of the recently qualified private universities of Cyprus or may have studied abroad, mainly in Greece and Britain. This implies that in-service, as well as pre-service teachers, receive different kinds of training which can be difficult to identify (Solsten 1991).

\section{Misconceptions and Preconceptions}

The term 'misconception' is the most widely one used in the literature, however this cannot be evidence this term is the correct term to use considering the purpose of this study. In most cases the term 'misconception' is used to describe children's notions that have the characteristics of incorrect models or theories, meaning that misconceptions are considered to be children's notions that differ from those generally accepted by the scientific community. In other words, misconceptions can be false or mistaken views, opinions or attitudes that can cause a barrier to understanding science (Treagust 1988; Guest 2003). It is evident that in most cases the term 'misconception' is used to describe older children's incorrect notions and the term has an obvious connotation of 'a wrong idea'. Additionally, research reported on common misconceptions in various areas of science indicates that this term is usually used in studies where children have been exposed to 'formal models or theories and have assimilated them incorrectly' (Driver and Easley 1978, 61). Conversely, the term 'preconception' implies that the ideas being expressed by children do not have the status of generalised understanding characteristics and in a situation where children have developed autonomous frameworks or have conceptualized their experience of the physical world their ideas will be called 'alternative frameworks' whereas (Clement et al. 1989). Preconceptions can also pose strong barriers to understanding science and can be detrimental to learning since they usually develop to be alternative frameworks which are even more difficult to change (Clement et al. 1989).

[Table 1 near here] 
For the purpose of this study the term 'preconceptions' will be used when referring to young children's ideas in science which have most likely been developed autonomously in relation with their experiences. Specifically, the term 'preconceptions' will refer to early years children's ideas that have been formed after limited or no teaching focusing on the specific area of the incorrect concept (see table 1). On the other hand the term alternative frameworks will be used to label older children's and teachers' notions that differ from those accepted by the scientific community as this group of learners has been exposed several times to formal models and theories. Both terms are being used to refer to erroneous ideas but each term refers to a different stage during a learner's journey.

Preconceptions arise from the children's own experiences (Worth 2000). Children's concepts develop as a result of experiences and socialisation, thus, everyday experiences will evolve with everyday ontological frameworks (Driver et al. 1994). Commonsense explanations might sometimes differ from the knowledge accepted by the scientific community; commonsense reasoning is usually free of rules in contrast to scientific reasoning (Driver et al. 1994). Language is another source of preconceptions since words, which are also used in everyday life but do not have the same meaning when used in science, can confuse children and lead to preconceptions (Hanuscin 2007). Similarly, alternative frameworks that children have at a later stage are usually similar to the misleading references used by the teachers in their everyday language in the classroom. Even though teachers need to use naturalistic language that the children will be familiar with, they must still be aware that natural expressions may, at the very least, slow down learning (Luisa et al. 1989).

Preconceptions can also arise when two or more learnt concepts get mixed up (Hanuscin 2007). Cohen and Kagan (1979) support that this verbal confusion is the most common way to form preconceptions which might lead to alternative frameworks. Children who have preconceptions can also convince others in a group to believe them (Snyder and Sullivan 1995). In conclusion, preconceptions and alternative frameworks arise from both verbal and conceptual confusion and can often be passed by one person to the other since usually people who hold such concepts are not aware that their concepts are not correct (Hanuscin 2007). This is why when learners are told that what they believe is incorrect, they find it difficult to overcome their beliefs, a reaction known as resistance to change, especially if they have held this beliefs for a long time (Hanuscin 2007). This is a vital idea for this paper since, based on social constructivism, knowledge is constructed collaboratively by building new understandings on previous conceptions; if the previous conceptions are incorrect, then the impact on learning is inevitable.

\section{The Early Years Socio Constructivist Teacher}

Children's learning in science is about understanding the world around them (Guest, 2003). The teacher is responsible for guiding children through the learning process based on children's abilities and prior knowledge and using the most effective methods of teaching (Loizou and Papademetri-Kachrimani 2011). Teachers are encouraged to use a variety of different forms of organising learning like play, learning centres, structured activities and in-depth study of topics (Kyriacou, 1998; Loizou and Papademetri-Kachrimani 2011). It is also necessary for them to understand how children learn in order to help them learn better (Ausubel, 1968). Social constructivism requires the learner to be actively involved in a joint enterprise with the teacher constructing new concepts and learning is not thought as a passive 
transmission of information from one individual to another (Atherton, 2009; Hoover, 1996; Jaworski, 1993). As a result, teachers have a complicated role, especially when teaching science.

Research has revealed that children hold preconceptions that do not agree with what is generally accepted by the scientific community (Snyder and Sullivan 1995). As an example, Bradley refers to a four-year-old child and his preconceptions about why it rains: "It rains because the sun shines on the top of the clouds and pushes the rain out and it rains down to us" (Bradley 1996, 3). Teachers need to be aware of the children's diverse and numerous experiences as they are important in order to help children develop scientific concepts, skills and attitudes in the world of teaching (Johnston 2005; Tirosh 2000). Children's preconceptions are less possible to be changed after a lesson which did not acknowledge them (Luisa et al. 1989).

However, previous research supports that teachers seldom have the time to identify children's preconceptions and are often forced to assume a certain base level for the children's knowledge (Chen et al. 2006). On the other hand, ignoring children's preconceptions with the hope that someday they will overcome them on their own is inappropriate since preconceptions can be further developed into more complicated alternative frameworks (Schmidt 1997). Children's preconceptions are essential for teaching since acknowledging them can help teachers plan lessons aiming to re-shape them into correct concepts. Social constructivism encourages the development of social learning in which children will be able to share ideas and construct their learning together (Hoover, 1996; Jaworski, 1993). Such lessons will enable children experience phenomena which contradict their current preconceptions for the purpose of inducing conceptual change (Valanides 2000; Pine et al. 2001). It is important for teachers to constantly develop their own science knowledge and try to eliminate their own alternative frameworks (Johnston 2005). Thus, the aim of this study was to investigate how teachers understand and respond to children's preconceptions.

\section{Methodology}

\section{Design}

Usually, a lot of different events take place in an early years classroom; teachers and children ask questions, new concepts are explained and children experiment and talk to each other (Valanides 2000). Considering this multidimensional element, a two phased research design was developed aiming to incorporate all the different events taking place and into developing a perceptive of how teachers understand and respond to children's preconceptions. The study employed the use of different methods to promote the collection of different types of data.

\section{Sample}

The sample for the first phase guided the selection of a sub-sample to follow up the in depth qualitative investigation of the second phase, which focused on individual teachers representing multiple case studies. The rational is that better understanding of the whole can be gained by focusing on key parts (Gerring 2007). This type of design is identified by Punch (2009) as having wide potential applicability in education research. The first phase included the collection of quantitative data through the use of a questionnaire, which was sent to one hundred and thirty five early years setting, seventy five of which were public and sixty were private kindergartens. A five-point Likert scale was used for the questionnaire which aimed to collect data on teachers' background, teachers' confidence when teaching science and teachers' satisfaction of 
their subject knowledge. Additional data on teacher training was selected during the first phase by interviewing two key informants science lecturers who were selected based on their academic profiles. This provided information on the population's characteristics and on the teacher training that teachers receive in regards to science.

[Table 2 near here]

With the completion of the first phase a hundred and five questionnaires were returned, all completed by female ${ }^{1}$ teachers, fifteen of whom indicated their willingness to participate in the second phase of the study as well. The researcher contacted all fifteen teachers and provided them with further information with regard to the study's timeframe. However, due to issues of time and distance proximity only eleven teachers participated in the second phase. All these early years teachers were females currently teaching at public or private early years schools, working with children between three and six years old.

\section{Materials and Procedure}

Eleven early years teachers participated in the second phase of the study (see table 2), which included interviews and observations. Aiming to integrate all different events happening in each early years classroom, a prudently planned classroom observation was employed which help to collect information on what was actually happening in the classroom during teaching and learning (Simpson and Tuson 2003; Wragg 1994). A lesson observation schedule was also developed which facilitated taking notes about the teachers' actions. The focus was on the teachers because focusing on them would help to select the necessary data to develop an understanding of their response to children's preconceptions. Data collection took place in the autumn, where for local climatic reasons teachers usually teach topics relevant to the weather e.g. rain, water, water cycle etc. For the purposes of data collection all the teachers that participated were asked to teach the water cycle phenomenon, in the same way that they would normally do if a researcher was not present. The commonality of content would enable the researcher to make direct comparisons. Also, the lessons were planned wholly by the teachers and observed by a researcher. Each lesson lasted for approximately forty minutes. To augment the observations, an audio recorder was used, in addition to the lesson observation, to capture the voices of the children and the teachers. The voice recorder was placed between the teachers and the children but a little closer to the teachers, as the main focus was on them. The audio recordings were transcribed ad verbatim. Each teacher also provided the lesson plan in advance which made clear the lesson objectives and the activities.

Semi-structured interviews were also conducted with all teachers who had the opportunity to clarify any issues in relation to the lesson something which enabled the researcher to appreciate events from the perspective of the teacher's eye (Silverman 2000). The interviews were necessary in order to identify teachers' understandings of children's preconceptions. The interviews lasted approximately forty minutes and included questions such as: 1) Can you provide your own definition of preconceptions? 2) Do you tend to identify children's preconceptions prior or while teaching a science lesson? 3) Do you acknowledge children's preconception when planning a science lesson? 4) Do you think that it is important for the teacher to be

\footnotetext{
${ }^{1}$ All questionnaires were completed by female early years teachers which indicates that the population is female dominated. This observation is also confirmed by the Ministry of Education based on a list of all in-service early years teachers, $99.9 \%$ of whom are women (www.eey.gov.cy).
} 
aware of children preconceptions and 5) Can preconceptions affect children's learning process? The questions were discussed in depth aiming to identify the 'how' and 'why' factors which helped to identify the teachers response and views on the importance of preconceptions when teaching science. The interviews, in conjunction with the observations and the questionnaires, provided rich data, enough to effectively answer the research questions.

\section{Ethical Considerations}

The study followed the BERA (2011) ethical guidelines, and permission to conduct the research was granted by the university's ethical committee in the UK and by the Ministry of Education and Culture in Cyprus. The schools were randomly selected from a school list provided by the Ministry of Education (MoEC 2006) (one out of every ten schools) which included both public and private early years schools. This sampling method ensured that all members of the population had the same probability to be selected into the sample and offered efficiency as there was no need to designate every population member (Merriam 1998). A letter was then sent to each school explaining the aim and methods of the study and requesting their participation. Firstly, the headteachers were asked to inform the school's early years teacher and ask for their consent to participate by signing the consent form, completing and returning the questionnaire with the use of the pre-paid posting service. The teacher was also informed that they could provide their details if they would like to participate in the second phase of the study (observations and interview).

The teachers, the parents and the children participating in the second phase of the study were informed of the data collection procedure and were requested to sign the consent for themselves and their children to participate. Verbal consent also was given by the children in addition to the written consent provided by their parents or guardians. Participants were also informed of their rights for privacy, anonymity and confidentiality and their right to withdraw at any time, and all of them gave their consent to participate.

\section{Results and Analysis}

The data were triangulated to encourage flexibility, increase validity and add some depth to the analysis (Hitchcock and Hughes, 1989). The instruments used provided qualitative and quantitative data, which were then merged through the interpretation-stage results. This process leaded to the development of the different themes which were then compared to the existing literature. There themes are presented in the discussion part whereas this part focuses on providing are insight on the process of analysis and on presenting the main results.

\section{Analysis}

The quantitative data was analysed with the use of the SPSS statistical package and a number of suitable tests were selected according to the data (Field 2009). The response rate was $77.78 \%$, which meant that SPSS tests could be used reliably (Field 2009). The co-efficiency of internal reliability (Cronbach's Alpha) was calculated at $+0.823^{2}$, with all questions included, which proved the reliability of the

\footnotetext{
${ }^{2}$ Cronbach's Alpha can lie between zero $(0)$ and +1 - any value over +0.7 is acceptable and indicates that the scale is reliable.
} 
scale. The results of the questionnaire analysis confirmed that the target population mostly consisted of white female teachers from which a total of $25.7 \%$ studied at the public University of Cyprus and 38,1\% at a private university in Cyprus. A percentage of $61.9 \%$, have been working for more than five years whereas $87.6 \%$ of them have not studied science during their compulsory higher education studies. All the teachers that participated in the second phase were working at governmental early years' schools at the time, with a mean of 18 years of working experience and with a mean of 22 children in their classes. Based on the information provided by the headteacher of each school, all children were coming from a medium socio-economic background and the mean of children's age present in the classroom during the lesson observation was 3.82 years old.

In addition, the qualitative data collected during the first and second phase was analysed based on the qualitative analytic method of the thematic approach with the use of N-Vivo (Bogdan and Biklen 2007). The thematic approach helped to identify, analyse and report themes within data which organises and describes data in detail (Braun and Clarke 2006). The first step followed while conducting the thematic analysis was to become familiar with the data. Then initial codes were generated and themes were identified and reviewed. During the next step themes were defined and named and finally the report was produced based on the themes (Braun and Clarke's 2006). The use of the N-Vivo supported this process by creating tree notes and free notes based on similarities that were identified (Bazeley and Jackson 2013). This enabled the analysis of the participants' experiences, ideas, thoughts and views with regard to children's preconceptions.

\section{Results}

The main results deriving from the data analysis suggest that $87,6 \%$ of the inservice teachers, did not have science as a main course during high school. In addition it seems that those teachers working in private early years schools feel more satisfied with a) their subject knowledge b) the training that they received during their studies, c) the equipment provided by their schools and d) their confidence when answering to the children's questions compared to early-years' teachers who work in public early years schools. Nevertheless, all teachers stated that there is a need for more training specifically on issues in relation to children's preconceptions, since most student teachers do not receive any training about the children's preconceptions. It is also important to mention that only half of them said that they feel confident when teaching science.

Furthermore, a positive correlation was identified between: a) teachers' satisfaction with their subject knowledge and their confidence to teach, b) teachers' topic preferences and their confidence when teaching that topic and c) teachers' topic preferences and their subject knowledge on that topic. However, a negative correlation was identified between: a) teachers' confidence to teach a topic and the teachers' opinion on the children's preconception on that topic and b) teachers' satisfaction with their subject knowledge about a topic and the teachers' opinion on the children's preconception on that topic.

The results also indicate that teachers usually do not identify the children's preconceptions perhaps because a) they might not have the necessary skills and knowledge to do this, b) they might not think that it is important to do so or c) they might not be aware of the existence of preconceptions. In addition, neither the Cypriot early years national curriculum nor reference book used by teachers take into account 
the children's preconceptions. Furthermore, all teachers agreed that it is very important to always have a lesson plan with clear learning objectives even though it takes them more time to prepare for a science lesson in comparison to other subjects. All the teachers that were observed provided a lesson plan but none of them included a specific learning objective or activity about the children's preconceptions in the lesson plan.

When teaching science and most of them supported that the best way to begin a science lesson is with a discussion-prediction part whereas the best way to finish it is with a summarising-evaluating part. From those observed, only one teacher started her lesson with an activity aiming to identify the children's prior knowledge and preconceptions and only two teachers dedicated time to work on the children's preconceptions even though preconceptions were expressed by children during all observations. All teachers agreed that it is helpful to be aware of the children's preconceptions about a science topic that they plan to teach, nonetheless most of them reported that they do not do something specific to help children correct their preconceptions and that tend to assume a certain base of knowledge for all children. However, most teachers agreed that the aim of the early years education is to help and guide children to develop their skills rather than correct their preconceptions. Finally, most teachers considered that preconceptions do not affect the children's learning and more than half of them agreed that it is acceptable for children to leave pre-primary school and still have preconceptions.

\section{Discussion}

This part draws together the results of the study deriving from both phases and discusses them in relation to the literature review. Specifically, it was important to discuss those themes that derive from more than one research collection method since the repetition of a theme signifies its importance. The data collected allowed all the research questions to be addressed and revealed interesting issues in regard to early years teaching of science and teachers' response to children's preconceptions. At this point, the main themes that need further discussion in order to answer the research questions are presented below. The discussion concludes with specific suggestions for teachers, policy, practice and further research.

\section{Teachers' views on identifying children's preconceptions}

The results suggest that most teachers recognise the importance of identifying children's preconceptions. However, they confessed that they do not always do so when planning or teaching a lesson. This was also confirmed during the lesson observations since only four teachers intentionally planned to identify the children's preconceptions. Teacher 2 specifically reported: "I think that it would be good to include an activity to identify preconceptions although I don't do that because, more or less, I know their concepts from what they say inside and outside the classroom. From experience I usually know what children at this age think". Chen et al. (2006) report that teachers usually assume that children know something when they actually do not and as teacher 11 added "Quite often I start teaching a topic assuming that children know something and then I realise that they actually don't. It is better to always have an activity that will help identify children's preconceptions before starting the lesson, no matter how well you know your class." Teacher 10 also discussed that: "If you do not uncover the children's preconceptions, you will begin your lesson with assumptions. This can lead to a pointless lesson because children will probably already know what you are teaching or not be able to follow, so it will 
be a waste of time." Successful lessons are more possible when teachers choose to elicit and acknowledge preconceptions (Allen 2014).

Teachers also recognise that planning an activity to uncover the children's preconceptions does not guarantee that all preconceptions will be identified. That is why according to teacher 11 , teachers should stop the lesson and work on preconceptions every time that a child expresses one during a lesson. This will positively influence the whole class because usually children share similar preconceptions (Valanides et al. 2000). As the teacher said "I always deal with preconceptions that come up during the lesson and this might take a few minutes or a series of lessons, depending on the preconception. I do that because usually children share similar preconceptions and this will help them construct their understanding." Teacher 9 agreed with the importance of stopping the lesson and responding to a preconception and as she said "While teaching 'Sinking and floating' a child insisted that wood doesn't sink based on experiences of floating boats made of wood. I asked the child to put a piece of wood in the water and the wood sank. The child though insisted that wood doesn't sink. I told him 'But you have seen it, it did sink' but the child insisted. The lesson was about sinking and floating so I couldn't ignore this preconception." The teacher continued by explaining how difficult it was to convince the specific child, which confirms Black and Lucas (1993) indication that children's preconceptions are remarkably resistant to change.

Teacher 5 added that it is easier for a teacher to promote children's conceptual development when knowing what they believe. As she said "If you do not identify children's preconceptions it is impossible to respond to them and thus more difficult to support children's understanding. If you care you will do it." Similarly, teacher 1 confessed that even when an expressed preconception does not have an obvious influence on the lesson, she feels that ignoring it would be wrong. She supported that teachers need to make a note of such incidents and organise further interactions to help children correct those preconceptions. She added that teachers need to acknowledge that children do not arrive at schools as a 'tabula rasa' something generally accepted by the education community since children enter the classroom with individual understandings of how the world works (Henriques 2002; Pine et al. 2001). It is important for teachers to consider this when planning and teaching science, since based on the results, teachers acknowledge the importance of identifying preconceptions but only four of them would actually do so in practice.

\section{Teachers' Response to Children's Preconceptions}

Teachers' acknowledge the importance of responding to children's preconceptions during a science lesson however, as it has already been mentioned, this is not always the case in practice. Teacher 3 discussed that there is no correct "recipe" when it comes to the children's preconceptions and as she explained "It depends on the specific preconception, on the teacher's instinct and on how the teacher thinks that it is better to handle it. I believe that there are a lot of ways to help children overcome their preconceptions. It depends on the specific children and the teacher." She added that teachers need to interact with children and note the preconceptions expressed inside and outside the classroom, similar to what Braund and Reiss (2004) suggest. "Teachers need to talk to their students outside the classroom, as well, because that is when the child will talk to you without fear and you will get to know what concepts the child has. I try to give children the opportunity to talk and express their ideas and listen to them without criticism. All ideas are respected and we should never make 
them feel uncomfortable to say what they believe." Listening to children can help teachers respond properly to preconceptions and it means providing time, space and choice for children to make a positive contribution to their learning by taking seriously what children express (Pugh and Duffy 2013). As teacher 4 supported "The best way to respond to the children's preconceptions is to listen to their needs and offer them experiences aiming to elicit and correct their preconceptions" something also suggested by Allen (2014).

Teachers 9,10 and 11 agreed that it is important for teachers to respond to preconceptions by helping the children understand which of their concepts are not correct and why. Teacher 9 explained that to accomplish this, children need opportunities to try things. Teacher 11 added that it is also important to give to each child the opportunity to actively participate during the experiments and also try all different ideas expressed by different children. She explained that "Trying everything that they say is the only way to convince them. And then, the results of the experiments should be written and kept on a visible place in the class to give them the opportunity to go back and see them. This helps them remember and recall information." In addition, teacher 5 mentioned that "It is important to create an environment where children will explore and discover the correct concepts and what you want them to learn on their own. You need to organise the activities in a way that children will discover and not 'give' them ready knowledge. If you just talk to them, they will not believe you. Even if they listen to you and repeat what you say, they will just do it to make you happy and not because they understand the meaning. Children need to be engaged in the learning in order to develop their understanding." This expresses the impact that the classroom environment can have on children's' motivation and learning (Kyriacou 1998). Social constructivist learning environments can provide multiple representations of the reality and give emphasis to knowledge construction and not to knowledge reproduction by providing learning environments such as real-world setting or case-based learning instead of predetermined sequences of instruction (Driver et al. 1994). These kinds of environments are ones that encourage thoughtful reflection on experiences and support collaborative construction of knowledge through social negotiation rather than through competition among learners for recognition (Atherton 2009; Hoover 1996; Jaworski 1993).

In addition, teachers 6,7 and 8 believed that it is not the early years teachers' responsibility to deal with preconceptions. Teacher 7 argued that the aim of early years education is not to teach science but to help children develop skills, which suggests a degree of ignorance from teachers towards the curriculum's aims on developing children's conceptual understanding (Loizou and Papademetri-Kachrimani 2011). Teacher 8 added that "When children grow up, they will understand and learn what is correct. It is not the main aim of the early years school to change these concepts because they will work on them at primary school and high school" Teacher 6 agreed and said "If those children that are usually faster and understand what you want to teach easily are not following you, then something is wrong. But, if is a child that always has difficulties with understanding what you teach, then it is ok. It may not be ready yet; some children may not be mature enough to accept what you teach". These responses designate an attempt from teachers to shift the responsibility from themselves to future teachers, arguing that they are not liable to respond to preconceptions since another teacher will deal with this issue in the future. This also indicates teachers' unawareness on inclusive education's principles such as providing equal opportunities to all children in accessing the curriculum (Pugh and Duffy 2013). 
Teachers need to recognise that their lessons need to match the children's needs and not the other way around. Teachers should differentiate their lessons to achieve inclusion and active engagement for all children irrespectively (Broderick et al. 2005) and acknowledging individual preconceptions should be part of this process.

Furthermore, teacher 6 referred to issues of lack of time which can lead to teachers not responding to children's preconceptions. As she said: "We can identify which children have preconceptions, but we have trouble dealing with these specific children individually because we do not have enough time." Lack of time is thought to be a serious issue for teachers and previous research indicates that teachers do not have enough time to handle children's preconceptions (Chen et al. 2006). One of the teachers confessed that "We often assume a certain basis of knowledge for all children and suppose that children know something when they actually do not because we don't have enough time to see what each and every child believes." The questionnaires revealed that $89,8 \%$ of teachers agree that the time pressure affects them negatively similarly to Collinson's and Fedoruk-Cook's (2000) argument. However, acknowledging preconceptions can help teachers save time; as teacher 1 described "If my students know what magnets attract, I will not waste a whole lesson talking about that which will save me time. I will cover that quickly and go on to the next thing about magnets. But, if I have a class that does not know anything about magnets, I will do it differently." Time pressure should not be used as an excuse; it should encourage teachers to interact with colleagues, share good practices and make decisions according to what is best for the children's development (Collinson and Fedoruk-Cook 2000).

\section{The Effect of Teachers' Understanding of Preconceptions' on Children's Learning}

Discussing teachers' views on the effect that preconceptions can have on the children's learning can help develop an understanding of the way that they respond to them. For example, teachers 2, 4 and 5 supported that preconceptions do not affect children's learning. Teacher 2 claimed that "Children pass through phases on their own and they change what they believe through time. I could say that their preconceptions are cute and they usually accept what we say during the lesson, even if they believed something else before. Only if something is really intense in their minds, it will be hard to change." Teacher 4 and 5 agreed that children usually accept what their teachers say and as teacher 4 said "They accept what we say very easily because we are their teacher and they believe us." This suggests that, even though the majority of the teachers seem to recognise the importance of identifying the children's preconceptions, it seems that they are always familiar with the obstacles created when ignoring preconceptions. This perhaps explains their tendency to avoid identifying them when developing a science lesson which lesson might fail to match the children's developmental learning. This can affect children's learning since they will not be able to fully achieve the learning objectives because preconceptions can make it more difficult for children to accept, learn and remember the correct and new concepts presented (Stepans and Kuehn 1995).

It is worth noting that not all teachers shared the above views. For example, teachers $1,3,9,10$ and 11 expressed the belief that preconceptions can be an obstacle for the children's learning. Teachers 9,10 and 11 were the only ones that specifically said that teachers should not ignore the children's preconceptions when planning or teaching a science lesson and teacher 9 argued that it is better to cover fewer topics in more depth rather than quickly go through a lot of topics without giving time to 
children to express their concepts and correct their preconceptions. In addition, teacher 3 said that "Preconceptions can have a negative impact on children; they can confuse children by mixing up the preconception with the correct concept. But, if what they know is correct, they successfully will build on it." This suggests that some teachers recognise that preconceptions can arise when pre-existing preconceptions and new concepts get mixed up, something which can be avoided if teachers include activities aiming to elicit the children's preconceptions (Hanuscin 2007).

However, the results signify that the majority of the teachers disregard that knowing children's preconceptions can help them plan lessons to support children's conceptual development (Schmidt 1997). Teachers' ignorance of the obstacles created when ignoring children's preconceptions can lead to children having difficulties in constructing their knowledge. Instruction which fails to identify children's preconceptions can leave children unchanged, whereas, instruction is significantly improved when teachers are aware of the considerations and the research findings on commonly held conceptions (M.D.E.S.S 2005). The results stress the importance of the teachers' role that needs to employ the appropriate tasks that will enable a constructive communicative process and will permit children to overcome their preconceptions (Ravanis and Bagakis 1998).

\section{Teachers' Training on Preconceptions}

The results suggest that the training that teachers receive with regard to science and children's preconceptions is limited. Based on the key informants' interviews, limited training opportunities result in teachers that do not have the necessary skills to deal with preconceptions. One of them specifically said that "Early years teachers do not identify preconceptions because they might not think that it is important to do so or because their teacher training did not provide them with the skills to do so". The teachers' interviews support this declaration since only teacher 9 had received some training about children's preconceptions during her teacher training studies. Teachers with less than ten years of teaching experience said that they did have a science module but that they did not recall any specific reference to the children's preconceptions. Teacher 4 particularly said that: "The science training that I received during my studies was very limited and we never even talked about the children's preconceptions. Teachers are not able to teach science successfully during the first year of their employment. We learn to teach through experience." Similarly, teacher 1 confessed that, at the beginning of her teaching career, her science teaching skills were limited and she did not even acknowledge the importance of preconceptions. As she explained "I just taught my planned lesson, based on what I learnt during my studies. I ignored preconceptions and thought that they weren't affecting my lesson. Now, I usually use the children's preconceptions to begin a lesson because I feel that this is the right thing to do, even though it takes more time." It seems it was through experience that these teachers recognised the importance of preconceptions and realised that ignoring them and hoping that children will overcome them on their own is unfair (Schmidt 1997).

Furthermore, teachers that completed their studies ten years ago or more report that they did not receive any science training at all during their studies. Teacher 11 reported: "I do not even remember having a module on science. We had a module called 'Ecology' which was more general and tried to provide us with knowledge about phenomena like the greenhouse phenomenon but not any knowledge or skills about teaching science". When the teachers were encouraged to share ideas about 
what would make them feel more confident, they suggested more seminars and conferences about teaching would be useful. Teacher 5 specifically said that "Teachers need better training before they start working and during their teaching years as well because things change. We need help to keep up with changes and people should come and teach us how to teach. We all need to observe lessons and see what mistakes we usually make and how we can correct them." Teachers argued that teacher training education needs to provide specific training about children's preconceptions and as teacher 11 added "Children do not have preconceptions only for science but for all the topics that are taught. A module preparing teachers on how to respond to preconceptions would be very helpful."

The questionnaires' results empower the above since based on them $87,6 \%$ of the teachers report that teacher training education did provide them with the necessary skills and knowledge to handle preconceptions. In addition, only $12,4 \%$ of the in service teachers have studied science during high school and $84,6 \%$ do not feel confident enough to deal with preconceptions. The questionnaires also revealed a positive correlation between teachers' satisfaction with their subject knowledge and their confidence to teach $(r=0,833)$ and teachers' lack of training and teachers' lack of confidence towards science $(\mathrm{r}=0,775)$. The study's results suggest that teachers do not feel satisfied with their science training experience and lack of confidence about teaching science. Literature reinforces that teachers' lack of confidence can have a negative impact on teaching and can lead teachers to avoid teaching science in general (Howitt 2006; Holroyd and Harlen 1996) something which indicates the need to improve teachers pre-service and in-service training with regard to science.

\section{Implications for Teachers, Teacher Education and Policy Makers}

Considering the above and the fact that early years teachers are expected to teach all subject areas but that they are not required to have a science background, it is important for teachers to clarify their own understanding of science and use this knowledge to inform their teaching in order to feel more confident (Tirosh 2000; Johnston and Gray 1999). Consequently, the teacher's role can be complicated and demanding which means that teacher training education needs to match this requirement. Policy makers and teacher training programs should ensure that early years teachers have acquired the necessary science knowledge and skills during their studies. Potential early years students could be examined to identify their scientific knowledge and preconceptions in order to help them improve their scientific understanding. Alternatively, more science modules could become obligatory for early years students. This would help future teachers to improve their scientific knowledge and acquire the necessary skills and knowledge to be more confident about teaching science. Teacher training programs should provide specific and targeted training to student teachers that would prepare them for future classroom situations; it should also help student teachers develop lifelong learning skills along with an attitude for additional training and improvement. In service teacher training should also be available to teachers throughout the year as part of their continuum professional development.

In addition, educators and policy makers should bear in mind that children construct their learning at different rates and their pre-school experiences may vary (Johnston 2005). In order to help children develop their ideas and conceptual understanding it is essential for time to be dedicated to identify children's preconceptions and provide opportunities to make links between individuals' ideas and other alternatives (Russell 
and Watt 1992). Teachers need to remember the importance of dedicating time to find out what preconceptions children have before teaching a new topic. This is essential, for teachers and headteachers, for example when developing their short-term and long-term planning, but also for policy makers and educational leaders who need to consider this when developing and evaluating the national curriculum.

Careful planning and preparation can lead to more effective science lessons with the use of a range of methods to identify preconceptions (M.D.E.S.E 2005). For example, classroom discussions and open-ended questions can be useful for sharing ideas and identifying preconceptions and can also allow children to think about their concepts and share them with others (Russell and Watt 1992; Wallace 2002). Examples of common preconceptions can also be useful to prompt discussion aiming to identify children's preconceptions (American Institute of Physics 1998). For instance, the teacher can present a common preconception in the form of a game and ask children to vote 'True' or 'False' and also encourage them to explain their response. Such games can help teachers to become aware of the preconceptions that children in their class have. A list of children's common preconceptions might also be useful for teacher training programmes when developing and when sharing learning material with student teachers. Children can also be encouraged to express their preconceptions through tasks such as mind-mapping activities or by discussing pictures. Children's drawings can also be helpful because they can help to identify what children believe or know. To do that, it is necessary to ask children to give an explanation of what they are drawing since the narrative that goes alongside the drawings can enable the teacher to access the children's thinking (Toolan 2001).

\section{Conclusion}

In conclusion, the study's results suggest that teachers in general agree with the importance of preconceptions and the fact that to address them they first need to identify them. They also agree that it is very important for a science lesson to begin with an activity that will help to identify the children's prior knowledge and preconceptions. The lesson should also end with another activity that will help summarise and find out if initial predictions were correct. As one of them stated 'It is very important for a teacher to be aware of the preconceptions students have because when children have preconceptions, it is more difficult for them to understand the correct concept and they cannot follow the lesson'. However, the results also indicate that teachers seldom have the time to identify children's preconceptions and tend to assume a certain base of knowledge. An important percentage of the teachers share the opinion that preconceptions cannot have a negative effect on children's understanding or conceptual development. This is further confirmed by the fact that only two of them actually included an activity which aimed to identify the children's preconceptions during the lesson observations. This is important since a lesson and the way that it is organised can affect the children's learning and their ability to get over their preconceptions (Atherton 2009; Hoover 1996). The fact that the majority of the teachers report that they do not intentionally respond to the preconceptions expressed by children during a lesson is vital and it should concern researchers, teachers, teacher educators and policy makers since it suggests that teachers are not properly informed and prepared for their complicated and demanding roles (Howitt 2006). There is a need for better training about preconceptions and the obstacles they can pose with regard to conceptual development. Teachers should remember that children need to be actively involved in the learning process and that activities should 
aim at constructing new concepts based on children's previous concepts and preconceptions (Harlen and Qualter 2004).

Teachers should not only be better informed about preconceptions, but they should also be better trained and prepared to work with the children's preconceptions in a way that will help children overcome them. It is important for teachers to be aware that children might fail to learn concepts when the lesson does not match their developmental learning stage or when they hold on to tenacious preconceptions that were not identified and considered during the stages of instruction (M.D.E.S.E 2005). All educators should keep in mind what one of the teachers highlighted during the interviews "Teachers cannot start a lesson by ignoring who they are teaching and what they know, the experiences that children have. Teachers need to know the existing preconceptions in order to help children re-shape them and construct their knowledge based on what they already know."

Although this study was prepared with care and has achieved its aims, there are always some potential limitations, mainly due to issues of lack of time and financial resources. The main limitation is the number of the participants for the second phase of the study. More interviews and observations could be conducted with more teachers to increase the number of the research participants. This would help increase the reliability and validity of the results which would make it safer to generalise the results as well. In the same way, a series of observations could be carried out instead of just one observation for each teacher and the questionnaires could have been sent to more schools, public and private, in order to gain further responses. Considering all the above and the importance of the results deriving from this study, further research is necessary to help identify particular ways to help and support teachers when identifying and responding to children's preconceptions. Further studies should involve more participants and also cover a range of topics in different subjects aiming to further investigate the complex issue of children's preconceptions. Further research that would reveal children's most common preconceptions with regard to specific topics and particular examples of how teachers can help children to overcome their preconceptions for each topic would be valuable and practical for teachers training programmes and experienced and newly qualified teachers as well.

\section{References}

Allen, M. 2014 Misconceptions in Primary Science. 2nd ed. Maidenhead: Open University Press.

Atherton, J. S. 2009. Learning and Teaching: Piaget's Developmental Theory. http://www.learningandteaching.info/learning/piaget.htm

American Institute of Physics. 1998. Children's Misconceptions About Science. http://amasci.com/miscon/opphys.html.

Bazeley, P., and Jackson, K. 2013. Qualitative Data Analysis with NVivo. 2nd edition. London: Sage

Braun, V. and Clarke, V. 2006. Using Thematic Analysis in Psychology. Qualitative Research in Psychology 3: 77-101.

Bitan-Friedlandera, M., Dreyfusa, A. and Milgromb, Z. 2004. Types of "teachers in training"': The Reactions of Primary School Science Teachers when Confronted 
with the Task of Implementing an Innovation. Teaching and Teacher Education 20, no. 6: 607-619

Bogdan, R. C., and Biklen. S. K. 2007. Qualitative Research for Education: An Introduction to Theory and Methods (5th edition). Pearson international.

Braund, M. and Reiss, M. 2004. Learning Science Outside the Classroom. USA and Canada: RoutledgeFalmer.

BERA (British Educational Research Association). 2011. Ethical Guidelines for Educational Research. http://www.bera.ac.uk/wpcontent/uploads/2014/02/BERA-Ethical-Guidelines-2011.pdf.

Broderick, A., Mehta-Parekh, H., and Reid, D. K. 2005. Differentiating Instruction for Disabled Students in Inclusive Classrooms. Theory Into Practice 44, no. 3: 194202.

Black, P. J. and Lucas, A. M. 1993. Children's Informal Ideas in Science. London and New York: RoutledgeFalmer.

Bradley, L. S. 1996. Children Learning Science. Oxford: Nash Pollack.

Chen, A.P., Kirkby, K.C., and Morin, P.J. 2006. Uphill Water Flow- An Example of the Crucial Role of student's Prior Knowledge in Geoscience Education. American Geophysical Union. http://adsabs.harvard.edu/abs/2006AGUFMED53A0847C.

Clement, J., Brown, D. E. and Zietsman, A. 1989. Not all preconceptions are misconceptions: finding 'anchoring conceptions' for grounding instruction on students' intuitions. International Journal of Science Education 11(special issue): 554-565.

Cohen, M. and Kagan, M. 1979. Where does the old moon go? http://www.eiu.edu/ scienced/329options/oldmoon.html.

Collinson, V. and Fedoruk-Cook, T. 2001. "I don't have enough time" - Teachers' Interpretations of Time as a Key to Learning and School Change. Journal of Educational Administration, 39, no. 3: 266 - 281.

Driver, R. and Easley, J. 1978. Pupil's Paradigms: A Review of Literature Related to Concepts Development in Adolescent Science Students. Studies in Science Education 5, no. 1: 61-84.

Driver, R., Asoko, H., Leach, J., Mortimer, E., and Scott, P. 1994. Constructing Scientific Knowledge in the Classroom. American Educational Research Association 23, no. 7: 5-12.

Field, A. P. 2009. Discovering Statistics Using SPSS and Sex and Drugs and Rock ' $n$ ' Roll. London: Sage Publications.

Gerring, J. 2007. Case Study Research: Principles and Practises. Cambridge: University Press.

Guest, G. 2003. Alternative Frameworks and Misconceptions in Primary Science. http://www.ase.org.uk/sci-tutors/Page1.

Harlen, W., and Qualter, A. 2004. The Teaching of Science in Primary Schools. London David Fulton Publishers: London. 
Holroyd, C., and Harlen, W. 1996. Primary Teachers' Confidence About Teaching Science and Technology. Research Papers in Education 11, no. 3: 323-335.

Hoover, W. A. 1996. The Practice Implication of Constructivism. SEDL Letter http://carbon.ucdenver.edu/ mryder/itc_data/constructivism.html

Hanuscin, D. 2007. Misconceptions in Science. http://www.indiana.edu/ w505a/studwork/deborah/.

Henriques, L. 2002. Children's Ideas About Weather. A Review of the Literature. School Science and Mathematics 102: 202-215.

Hitchcock, G. and Hughes, D. 1989 Research and the Teacher: A Qualitative Introduction to Scholl- based Research. London \& New York: Routledge.

Howitt, C. 2006. Pre-Service Elementary Teachers' Perceptions of Factors in an Holistic Methods Course Influencing their Confidence in Teaching Science. Research in Science Education. 37: 41-58

Johnston, J. 2005. Early Explorations in Science. (2 ${ }^{\text {nd }}$ Edition.). Maidenhead: Open University Press.

Johnston, J., and Gray, A. 1999. Enriching Early Scientific Learning. BuckinghamPhiladelphia: Open University Press.

Jaworski, B. 1993. Constructivism and Teaching- The Socio-cultural Context. http://www.grout.demon.co.uk/Berbara/chreods

Kambouri, M., Briggs, M., and Cassidy, M. 2011. Children's Misconceptions and the Teaching of Early Years Science: A Case Study. Journal of Emergent Science 2, no. 2: 7-16.

Kyriacou, C. 1998. Essential Teaching Skills. Spain: GraphyCems

Loizou, E. and Papademetri-Kachrimani, C. 2011. Curriculum for Pre-School Education (original in Greek). Cyprus: Ministry of Education.

Luisa, M., Veiga, F., C,S., V., D. J., Pereira, C., and Maskill, R. 1989. Teachers' Language and Pupils' Ideas in Science Lessons: Can Teachers Avoid Reinforcing Wrong Ideas? International Journal of Science Education 11, no. 4: 465-479.

Merriam, S. B. 1998. Qualitative Research and Case Study Applications in Education. San Francisco: Jossey-Bass Publishers.

MoEC (Ministry of Education and Culture). 1996. Cyprus National Curriculum. Nicosia: Department of Development of Educational Programs.

M.D.E.S.E (Missouri Department of Elementary and Secondary Education). 2005. Misconceptions in Science. http://printfu.org/read/alerts-to-student-difficultiesand-misconceptions-in-science-9e8a.html.

Nussbaum, J. 1989. Classroom Conceptual Change: Philosophical Perspectives. International Journal of Science Education 11, no. 5: 530-540.

Pine, K., Messer, D. and John, K. S. 2001. Children's Conceptions of the Changes of State of Water. Journal of Research in Science Teaching 19, no. 1: 79-96.

Pugh, G and Duffy, B. 2013. Contemporary Issues in the Early Years. London: Sage 
Punch, K. F. 2009. Introduction to Research Methods in Education. London: Sage Publications.

Ravanis, K., and Bagakis, G. 1998. Science Education in Kindergarten: Sociocognitive perspective. International Journal of Early Years Education 6, no. 3: 315-327.

Russell, T., and Watt, D. 1992. Primary Space Project Research Report. Evaporation and Condensation. Liverpool: University Press.

Schmidt, H.J. 1997. Students' Misconceptions- Looking for a Pattern. Science Education 81, no. 2: 123-135.

Silverman, D. 2000. Doing Qualitative Research: A Practical Handbook. London: Sage Publications.

Simpson, M., and Tuson, M. 2003. Using Observations in Small-scale Research: A Beginner's Guide. Glasgow: Scottish Council for Research in Education.

Snyder, T., and Sullivan, H. 1995. Brief Research Report- Cooperative and Individual Learning and Student Misconceptions in Science. Contemporary Educational Psychology 20: 230-235.

Solsten, E. 1991. Cyprus: A Country Study. Washington: GPO for the Library of Congress.

Stepans, J., and Kuehn, C. 1995. Children's conceptions of weather. Science and Children 23, no. 1: 44-47.

Tirosh, D. 2000. Enhancing Prospective Teachers' Knowledge of Children's Conceptions: The Case of Division of Fractions. Journal for Research in Mathematics Education. Journal for Research in Mathematics Education 31, no. 1: 5-25.

Toolan, M. J. 2001. Narrative: A Critical Linguistic Introduction (2nd ed.) London: Routledge.

Treagust, D. F. 1988. Development and Use of Diagnostic Tests to Evaluate Students' Misconceptions in Science. International Journal of Science Education 10, no. 2: $159-169$

Valanides., N. 2000. Primary Student Teachers' Understanding of the Process and Effects of Distillation. Chemistry Education: Research and Practice in Europe 1 no. 3: 355-364.

Valanides, N., Gritsi, F., Kampeza, M., and Ravanis, K. 2000. Changing Pre-School Children's Conceptions of the Day/ Night Cycle. International Journal of Early Years Education 8, no. 1: 27- 39.

Wallace, B. 2002. Teaching Thinking Skills across the Early Years: A Practical Approach for children aged 4-7. London: David Fulton Publishers.

Worth, K. 2000. The Power of Children's Thinking. http://www.nsf.gov/pubs/2000/nsf99148/pdf/nsf99148.pdf.

Wragg, E. C. 1994. An Introduction to Classroom Observation. London: RoutledgeFalmer. 
Zembylas, M. 2002. The Global, the Local, and the Science Curriculum: A Struggle for Balance in Cyprus. International Journal Science in Education 24, no. 5: 499-519. 